\title{
Cytarabine Induced Acute Cerebellar Syndrome during Hyper-CVAD Treatment for B-Cell Acute Lymphoblastic Leukemia
}

\author{
Phu Ngoc Tran ${ }^{a} \quad$ Xiao-Tang Kong ${ }^{b}$ \\ aDivision of Hematology-Oncology, Department of Medicine, Chao Family Comprehensive \\ Cancer Center, University of California Irvine School of Medicine, Orange, CA, USA; \\ ${ }^{b}$ Neuro-Oncology Program, Department of Neurology, University of California Irvine \\ School of Medicine, Orange, CA, USA
}

\section{Keywords}

Acute cerebellar syndrome - Cytarabine - Acute lymphoblastic leukemia $\cdot$ Ataxia . Chemotherapy $\cdot$ Hyper-CVAD $\cdot$ Neurotoxicity

\begin{abstract}
Acute cerebellar syndrome can be caused by high doses of cytarabine, but it has not been described in patients with acute lymphoblastic leukemia (ALL) who received hyper-CVAD chemotherapy. Herein, we report two cases with histories of positive Philadelphia chromosome B-cell ALL who developed acute cerebellar syndrome after the exposure to relatively low doses of cytarabine in the second cycle of hyper-CVAD regimen. The cerebellar symptoms were attenuated by cytarabine discontinuation and administration of steroids. This case report provides detailed discussions on the treatments, the potential role of methotrexate in cytarabine-induced cerebellar syndrome, and the importance of carefully monitoring renal function during hyper-CVAD treatment.

(C) 2017 The Author(s)

Published by S. Karger AG, Basel
\end{abstract}




\section{Case Reports in Neurology}

\section{Introduction}

Hyper-CVAD is one of the most frequently used regimens for routine treatment of adult acute lymphoblastic leukemia (ALL) in many countries [1]. Hyper-CVAD regimen includes alternating cyclophosphamide, vincristine, doxorubicin, and dexamethasone in the part A of a cycle and methotrexate and cytarabine in the part B of the same cycle [2]. Although cytarabine-induced cerebellar syndrome is common at high doses of cytarabine (total dose $\geq 36$ $\mathrm{g} / \mathrm{m}^{2}$ ), it rarely occurs at low doses (total dose $<15 \mathrm{~g} / \mathrm{m}^{2}$ ) $[3,4]$. In this article, we report two cases with positive Philadelphia chromosome B-cell ALL who developed cerebellar syndrome during the second cycle of hyper-CVAD at total doses of 16 and $18 \mathrm{~g} / \mathrm{m}^{2}$ of cytarabine, far lower than the reported high doses. We will discuss the potential mechanisms, early detection and treatment of cytarabine-induced cerebellar syndrome, and possible role of methotrexate in cytarabine-induced cerebellar syndrome during hyper-CVAD regimen.

\section{Case Reports}

\section{Case 1}

A 46-year-old Hispanic male presented to the hospital for right arm pain and he had a leukocyte count of $71,000 / \mathrm{mm}^{2}$, platelet $44,000 / \mathrm{mm}^{2}$, and LDH $6,815 \mathrm{U} / \mathrm{L}$. Bone marrow biopsy showed $80-90 \%$ pre-B ALL. Fluorescence in situ hybridization of the bone marrow sample was positive for Philadelphia chromosome. There was no leukemic involvement of the cerebrospinal fluid (CSF). The patient was started on induction chemotherapy with hyper-CVAD and dasatinib. He received the first cycle and part A of the second cycle of hyperCVAD regimen without significant complications. Repeated peripheral blood BCR/ABL p210 after part A of cycle 2 was $0.02 \%$. Four weeks later, he was admitted for chemotherapy with part B (methotrexate and cytarabine) regimen of the second cycle. His renal function was normal on admission with creatinine $0.9 \mathrm{mg} / \mathrm{dL}$ (GFR $>60 \mathrm{~mL} / \mathrm{min} / 1.73 \mathrm{~m}^{2}$ ) (Table 1). On day 1 , the patient received methotrexate and on day 2 and day 3 , he received cytarabine at $3 \mathrm{~g} / \mathrm{m}^{2}$ every $12 \mathrm{~h}$ without complaints. He then developed mild renal insufficiency with serum creatinine $1.7 \mathrm{mg} / \mathrm{dL}$ (GFR $53 \mathrm{~mL} / \mathrm{min} / 1.73 \mathrm{~m}^{2}$ ). Clinically, he was asymptomatic. On day 4, cytarabine was suspended because of the elevated serum creatinine. The patient had fever and chills without neutropenia, which prompted empiric antibiotics and extensive infection workup. As a result, no infection was found and his fever resolved the next day. Two days later, cytarabine was resumed with attenuated doses at $1 \mathrm{~g} / \mathrm{m}^{2}$ every $12 \mathrm{~h}$ for 2 days, bringing the total dose of cytarabine to $16 \mathrm{~g} / \mathrm{m}^{2}$ (total dose $36 \mathrm{~g}$ ) in cycle 2 . At the end of the above chemotherapy course, the patient developed confusion, dizziness, nystagmus, slurred speech, unstable gait, and then dysphagia. Neurological exam found an awake and alert male with reduced attention, severe telegraphic dysarthria, dysmetria, truncal (greater than limb) ataxia, and inability to ambulate. Sensation was normal and motor strength was $5 / 5$ bilaterally. The stroke team evaluated the patient and ruled out stroke. Brain MRI was unremarkable. Electroencephalogram (EEG) showed diffuse encephalopathy and lateralized dysfunction of the left hemisphere, mostly in the left frontal lobe (Table 2). CSF analysis showed glucose of $88 \mathrm{mg} / \mathrm{dL}$ (41-70 mg/dL), protein $43 \mathrm{mg} / \mathrm{dL}(15-45 \mathrm{mg} / \mathrm{dL})$, and $1 \mathrm{nu}-$ cleated cell $/ \mathrm{mm}^{2}\left(0-5\right.$ cells $\left./ \mathrm{mm}^{3}\right)$. CSF bacterial culture, Cryptococcus neoformans antigen, 


\section{Case Reports in Neurology}

venereal disease research laboratory test (VDRL), West Nile, HSV, viral culture, and fungal culture were all negative. His chemotherapy was discontinued. He was started on dexamethasone $4 \mathrm{mg}$ every $6 \mathrm{~h}$ for suspicious cytarabine-induced acute cerebellar syndrome. His encephalopathy symptoms resolved quickly within 3-4 days. However, his dysarthria and trunk ataxia only had mild improvement. After 1 week, high-dose dexamethasone was switched to a large dose of methylprednisolone (1 $\mathrm{g}$ a day) based on a case report in the literature [5]. However, the patient developed Clostridium difficile colitis after 2 days of treatment, which led to rapid discontinuation of methylprednisolone. One week later, he developed sepsis in the setting of neutropenia. He has made a slow and partial neurologic improvement over the course of a few months, receiving occupational and physical therapies in the rehabilitation unit. He was never re-challenged with cytarabine and has been on dasatinib since then. His pre-B ALL is still in complete remission with BCR-ABL PCR $<0.0032 \%$ more than 1 year from diagnosis.

\section{Case 2}

A 56-year-old Asian male initially presented with fatigue and weakness and was found to have leukocytosis at $22,300 / \mathrm{mm}^{2}$ and thrombocytopenia at $35,000 / \mathrm{mm}^{2}$. Peripheral blood flow cytometry was consistent with B-cell ALL. The patient was started on hyperCVAD and dasatinib. After cycle 1 of the hyper-CVAD regimen, the patient was found to have bilateral frontal small spontaneous subdural hygroma (3 and $9 \mathrm{~mm}$ thickness) but did not require surgical intervention. He also developed mild renal dysfunction with a new baseline of serum creatinine at 1.2-1.4 mg/dL (GFR $60-52 \mathrm{~mL} / \mathrm{min} / 1.73 \mathrm{~m}^{2}$ ), in comparison with his normal baseline of serum creatinine at $0.8 \mathrm{mg} / \mathrm{dL}$ (GFR $>60 \mathrm{~mL} / \mathrm{min} / 1.73 \mathrm{~m}^{2}$ ) prior to any chemotherapy. He tolerated part A of the second cycle without complications. Subsequently, 4 weeks later, he came to the hospital for part B of cycle 2 of the hyper-CVAD regimen, which consisted of methotrexate and cytarabine. On day 1 , he received methotrexate. On day 2 , he received cytarabine $3 \mathrm{~g} / \mathrm{m}^{2}$ every $12 \mathrm{~h}$ uneventfully, while his creatinine was $1.2 \mathrm{mg} / \mathrm{dL}$ (GFR $>60 \mathrm{~mL} / \mathrm{min} / 1.73 \mathrm{~m}^{2}$ ). He continued with $3 \mathrm{~g} / \mathrm{m}^{2}$ every $12 \mathrm{~h}$ of cytarabine on day 3 and day 4. On day 5 , he developed fever without neutropenia, which prompted empiric antimicrobial treatment with cefepime, vancomycin, acyclovir, and voriconazole. Workup for infection was negative. Cytarabine was suspended on day 5 . Up to day 5 , he received $18 \mathrm{~g} / \mathrm{m}^{2}$ of total cytarabine (total dose was $36 \mathrm{~g}$ ) in cycle 2 . On day 6 , he developed altered mental status, dysarthria, dysphagia, and ataxia. Neurologic exam revealed lethargy with poor attention, severe dysarthria, truncal and limb ataxia, dysdiadochokinesia, and dysmetria on bilateral finger-to-nose and heel-to-shin tests. He also had an ataxic gait and was unable to ambulate, with normal sensation and motor strength. Stroke evaluation showed negative findings. Cerebral fluid analysis revealed a glucose level of $65 \mathrm{mg} / \mathrm{dL}(41-70 \mathrm{mg} / \mathrm{dL})$, protein 33 $\mathrm{mg} / \mathrm{dL}(15-45 \mathrm{mg} / \mathrm{dL})$, erythrocytes $631\left(0 \mathrm{~mm}^{3}\right)$, nucleated cells $2\left(0-5 / \mathrm{mm}^{3}\right)$. Cerebral fluid analysis of Cryptococcus neoformans antigen, VDRL, viral and bacterial studies were all negative. MRI of the brain revealed the prior bilateral improved small subdural hygroma and an interval Ommaya placement at the right hemisphere without acute infarction, intracranial hemorrhage, intracranial lesion, or hydrocephalus. EEG showed a mild degree of relative attenuation and slowing activity in the right hemisphere. There was also a mild degree of generalized encephalopathy present. No epileptiform discharges or electrographic seizure were observed (Table 2). Subsequently, the patient was diagnosed with cytarabine-induced 


\section{Case Reports in Neurology}

Case Rep Neurol 2017;9:114-120

DOI: $10.1159 / 00046892$

(C) 2017 The Author(s). Published by S. Karger AG, Basel www.karger.com/crn

Tran and Kong: Cytarabine Induced Acute Cerebellar Syndrome during Hyper-CVAD

Treatment for B-Cell Acute Lymphoblastic Leukemia

cerebellar syndrome. Cytarabine was discontinued. He was started on dexamethasone $12 \mathrm{mg}$ every $6 \mathrm{~h}$ and experienced significant improvement in mental status and moderate improvement in cerebellar symptoms. Repeat neurological exam after 3 days of treatment revealed normal concentration and orientation, slow speech with moderate dysarthria, and intact finger-to-nose tests without limb ataxia. He still had trunk ataxia. He had mild to moderate dysarthria and was able to ambulate with assistance after 5-7 days of treatment. His dexamethasone was discontinued after 1 week and he was started on prednisone taper. Unfortunately, he developed invasive mucormycosis of the hard palate on day 14 and required urgent tissue debridement. His prednisone was tapered off quickly within 3 days. He did well after the surgery and continued to recover neurologically through physical therapy, occupational therapy, and speech therapy. Currently he has only mild dysarthria and is able to ambulate independently. His B-ALL is still in complete remission.

\section{Discussion}

Acute cerebellar syndrome has not been described in the treatment of B-cell ALL patients with hyper-CVAD regimen in the literature. Our two cases shared similar baseline characteristics such as onset of acute cerebellar syndrome after receiving relatively low doses of cytarabine in the second cycle of hyper-CVAD, mild renal dysfunction, and being responsive to cytarabine discontinuation and steroid treatment.

Cytarabine is metabolized $80-90 \%$ by the liver to uracil arabinoside (inactive metabolite). Approximately $10-20 \%$ of cytarabine is metabolized to aracytidine triphosphate (active metabolite) [6]. Cytarabine primarily undergoes renal excretion as uracil arabinoside within $24 \mathrm{~h} \mathrm{[6]}$. Both cytarabine and its metabolites can cause neurotoxicity through a DNA synthesis-independent process since adult neurons are postmitotic [7]. The exact mechanism of cytarabine neurotoxicity is unknown, but autopsies revealed loss of Purkinje cells in the cerebellum and reactive proliferation of glial cells [8]. In addition, cytarabine may cause patchy loss in the molecular and granular layers of the cerebellum but rarely affects the deep cerebellar nuclei [9]. The half-life of cytarabine in the CSF is about $2 \mathrm{~h}$ but can be longer if the recipient has renal insufficiency. Renal insufficiency has been reported as a major risk factor for cytarabine neurotoxicity in several reports $[3,4,10]$. In our first case, the patient had clear evidence of renal insufficiency developed after methotrexate use in cycle $2 \mathrm{~B}$ and became worse prior to occurrence of neurotoxicity, suggesting that methotrexate might have played an indirect role in the development of acute cerebellar syndrome in hyper-CVAD regimen [11]. Our second case developed very mild renal dysfunction after cycle 1B treatment. Even though his serum creatinine was only slightly elevated $(1.2 \mathrm{mg} / \mathrm{dL}$ with GFR $>60$ $\left.\mathrm{mL} / \mathrm{min} / 1.73 \mathrm{~m}^{2}\right)$ compared to his normal baseline $(0.8 \mathrm{mg} / \mathrm{dL}$ with GFR $>60 \mathrm{~mL} / \mathrm{min} / 1.73$ $\mathrm{m}^{2}$ ), cytarabine-induced cerebellar toxicity still occurred. These two cases indicated that prompt optimizing of renal function and dose adjustment or suspension of cytarabine are important.

In our two cases, the cumulative cytarabine doses were 16 and $18 \mathrm{~g} / \mathrm{m}^{2}$, respectively, in cycle 2 (Table 1). These doses are much lower than the reported high-dose cytarabine $[3,4]$. Therefore, we recommend carefully monitoring renal function during hyper-CVAD, especial- 


\section{Case Reports in Neurology}

Case Rep Neurol 2017;9:114-120

DOI: $10.1159 / 00046892$

(C) 2017 The Author(s). Published by S. Karger AG, Basel www.karger.com/crn

Tran and Kong: Cytarabine Induced Acute Cerebellar Syndrome during Hyper-CVAD

Treatment for B-Cell Acute Lymphoblastic Leukemia

ly during the second cycle of hyper-CVAD treatment, and modifying cytarabine administration immediately if any deterioration in renal function is detected.

Our cases did not have cerebellar symptoms at the first day of cytarabine infusion but after 3-4 days of use in the second cycle. The delayed occurrence of cerebellar toxicity supports the theory that cytarabine-induced cerebellar syndrome is related to cellular accumulation and retention of cytarabine [12]. It is important to emphasize that the cerebellar toxicity did not occur in the first cycle of hyper-CVAD but in the second cycle in both our cases, suggesting that immune-mediated mechanism by cytarabine might be also involved [5], in addition to accumulated toxicity.

Diagnosis of acute cerebellar syndrome requires a high index of suspicion in patients receiving cytarabine after ruling out other CNS pathologies. Acute cerebellar syndrome usually begins with cerebral effects (i.e., somnolence, confusion, disorientation, memory loss, and cognitive dysfunction) and cerebellar signs such as dysarthria, ataxia, dysphagia, and unsteady gait as in our two cases. In addition to the above common features, we also found that fever without evidence of infection occurred even earlier than neurological symptoms. Since only noticed in two cases, we cannot conclude that fever is definitely part of acute neurotoxicity, which deserves further investigations in the future. We also observed that truncal ataxia was more prominent than limb ataxia. And the recovery in limb ataxia was earlier than in truncal ataxia. Improvement of the neurological symptoms appeared as the following sequences: cerebral function including but not limited to somnolence, confusion, and memory impairment, followed by cerebellar function in the sequence of nystagmus, dysmetria, limb ataxia, trunk ataxia, unsteady gait, and dysarthria. In line with the cases reported in the literature, we did not find any abnormalities in brain MRI or CSF studies. EEG showed changes of encephalopathy.

There is no standardized treatment for cytarabine-induced acute cerebellar syndrome. In our cases, the patients responded favorably to the cytarabine discontinuation and the use of steroids. Although it is unclear how important the role is that the steroid played in the treatment of cytarabine-induced cerebellar syndrome, we recommend using a high dose of dexamethasone in addition to discontinuation of cytarabine, because of the rapid recovery of altered mental status and moderate improvement of cerebellar symptoms after receiving dexamethasone in the second case.

Among various types of steroid, we consider dexamethasone a good choice because of its high potency of anti-inflammation. Our first patient was initially treated with $4 \mathrm{mg}$ dexamethasone every $6 \mathrm{~h}$, which led to resolution of encephalopathy and mild improvement of cerebellar symptoms. Based on a prior case report [5], we switched him to large dose of methylprednisone hoping to have more improvement of cerebellar symptoms. Unfortunately, he developed Clostridium difficile colitis, which prompted a rapid steroid taper. The second patient was treated with $12 \mathrm{mg}$ dexamethasone every $6 \mathrm{~h}$ and his encephalopathy and cerebellar symptoms improved significantly within 1 week. The rationale for high-dose dexamethasone is based on the experience of treating acute encephalopathy and chemical meningitis stemming from intrathecal cytarabine $[13,14]$. Because both our patients eventually developed systemic infection in the setting of significant neutropenia after 9-14 days of steroid use, we recommend 1 week of high-dose steroid use in the treatment of cytarabineinduced acute cerebellar syndrome. In our observation, the benefits from steroid appeared 
early within 1 week from initiation. Hence, the risk and benefit ratio favors early steroid initiation and rapid tapering or discontinuation after a 1-week use.

Neurologic rehabilitation is another treatment component that helps improve neurologic deficits. Even with rehabilitation management, our patients had only achieved partial neurologic recovery; therefore, prevention and early recognition of cytarabine-induced cerebellar toxicity are essential in order to avoid its long-term complications.

\section{Statement of Ethics}

The authors have no ethical conflicts to disclose.

\section{Disclosure Statement}

The authors declare no conflict of interest.

\section{References}

1 Buyukasik Y, Acar K, Kelkitli E, Uz B, Serefhanoglu S, Ozdemir E, et al: Hyper-CVAD regimen in routine management of adult acute lymphoblastic leukemia: a retrospective multicenter study. Acta Haematol 2013;130:199-205.

2 Kantarjian HM, O’Brien S, Smith TL, Cortes J, Giles FJ, Beran M, et al: Results of treatment with hyperCVAD, a dose-intensive regimen, in adult acute lymphocytic leukemia. J Clin Oncol 2000;18:547-561.

-3 Yeshurun M, Marsot Dupuch K: Acute cerebellar syndrome following intermediate-dose cytarabine. Br J Haematol 2001;113:846.

-4 de la Maza Cantero SS, Martín AJ, de Felipe Mimbrera A, Corral ÍC: Cerebellar toxicity due to cytarabine: a series of 4 cases. Neurologia 2016;31:491-492.

-5 Malhotra P, Mahi S, Lal V, Kumari S, Jain S, Varma S. Cytarabine-induced neurotoxicity responding to methyl prednisolone and research, Chandigarh, India. Am J Hematol 2004;77:416.

6 Cytarabine (prescribing information). Rockford IMID.

7 Martin D, Wallace T, Johnson E: Cytosine arabinoside kills postmitotic neurons in a fashion resembling trophic factor deprivation: evidence that a deoxycytidine-dependent process may be required for nerve growth factor signal transduction. J Neurosci 1990;10:184-193. Pellier I, Leboucher B, Rachieru P, Ifrah N, Rialland X: Flushing out of cerebrospinal fluid as a therapy for acute cerebellar dysfunction caused by high dose of cytosine arabinoside: a case report. J Pediatr Hematol Oncol 2006;28:837-839.

-9 Winkelman MD, Hines JD: Cerebellar degeneration caused by high-dose cytosine arabinoside: a clinicopathological study. Ann Neurol 1983;14:520-527.

10 Hasle H: Cerebellar toxicity during cytarabine therapy associated with renal insufficiency. Cancer Chemother Pharmacol 1990;27:76-78.

11 Widemann BC, Adamson PC: Understanding and managing methotrexate nephrotoxicity. Oncologist 2006;11:694-703. Baker WJ, Royer GL, Weiss RB: Cytarabine and neurologic toxicity. J Clin Oncol 1991;9:679-693. Glantz MJ, LaFollette S, Jaeckle KA, Shapiro W, Swinnen L, Rozental JR, et al: Randomized trial of a slowrelease versus a standard formulation of cytarabine for the intrathecal treatment of lymphomatous meningitis. J Clin Oncol 1999;17:3110-3116.

14 Van Den Berg H, Van Der Flier M, van de Wetering M: Cytarabine-induced aseptic meningitis. Leukemia 2001;15:697-699. 
Table 1. Patient baseline characteristics and cytarabine exposure in hyper-CVAD

\begin{tabular}{|c|c|c|c|c|c|c|c|c|}
\hline Case & $\begin{array}{l}\text { Age, } \\
\text { years }\end{array}$ & Cancer & Cycle & $\begin{array}{l}\text { Total dose of } \\
\text { cycle } 2 \mathrm{~B}\end{array}$ & $\begin{array}{l}\text { Normal baseline Cr prior to } \\
\text { any chemotherapy, } \mathrm{mg} / \mathrm{dL}\end{array}$ & $\begin{array}{l}\text { Cr prior to } \mathrm{CNS} \\
\text { toxicity, } \mathrm{mg} / \mathrm{dL}\end{array}$ & LFTs & CNS disease \\
\hline 1 & 46 & $\mathrm{Ph}^{+} \mathrm{ALL}, \mathrm{CSF}^{-}$ & $2 \mathrm{~B}$ & $16 \mathrm{~g} / \mathrm{m}^{2}(36 \mathrm{~g})$ & 0.8 & 1.9 & WNL & none \\
\hline 2 & 56 & $\mathrm{Ph}^{+} \mathrm{ALL}, \mathrm{CSF}^{-}$ & $2 \mathrm{~B}$ & $18 \mathrm{~g} / \mathrm{m}^{2}(36 \mathrm{~g})$ & 0.8 & 1.2 & WNL & $\begin{array}{l}\text { recent subdural } \\
\text { hygroma }\end{array}$ \\
\hline
\end{tabular}

$\mathrm{Ph}^{+}$, Philadelphia chromosome positive; ALL, acute lymphoblastic leukemia; CNS, central nervous system; CSF, cerebrospinal fluid; WNL, within normal limit; LFTs, liver function tests; $\mathrm{Cr}$, creatinine.

Table 2. Clinical characteristics, diagnosis, management, and outcomes

\begin{tabular}{|c|c|c|c|c|c|c|}
\hline Case & $\begin{array}{l}\text { Clinical } \\
\text { manifestation }\end{array}$ & MRI & EEG & Treatment & Recovery & Outcomes \\
\hline 1 & $\begin{array}{l}\text { Confusion, severe } \\
\text { dysarthria, nystagmus, } \\
\text { truncal >limb ataxia, } \\
\text { dysmetria, dysphagia, } \\
\text { unsteady gait }\end{array}$ & $\begin{array}{l}\text { No acute stroke, } \\
\text { hemorrhage, } \\
\text { mass, or other } \\
\text { acute intracranial } \\
\text { process }\end{array}$ & $\begin{array}{l}\text { Mild diffuse } \\
\text { encephalopathy, } \\
\text { lateralized dysfunction } \\
\text { of the left hemisphere, } \\
\text { mostly in the left } \\
\text { frontal lobe }\end{array}$ & $\begin{array}{l}\text { Dex, } \\
\text { methylpred }\end{array}$ & $\begin{array}{l}\text { Partial with moderate } \\
\text { dysarthria, trunk } \\
\text { ataxia, and unsteady } \\
\text { gait }\end{array}$ & $\begin{array}{l}\text { Complete } \\
\text { remission of } \\
\text { ALL, residual } \\
\text { neurologic } \\
\text { deficits }\end{array}$ \\
\hline 2 & $\begin{array}{l}\text { Somnolence, dysarthria, } \\
\text { dysmetria, trunk and } \\
\text { limb ataxia, dysphagia, } \\
\text { unsteady gait }\end{array}$ & $\begin{array}{l}\text { Stable subacute subdural } \\
\text { hematoma, no acute } \\
\text { stroke, hemorrhage, or } \\
\text { abnormal parenchymal } \\
\text { signaling }\end{array}$ & $\begin{array}{l}\text { Diffuse slowing } \\
\text { background with } \\
\text { attenuation in the } \\
\text { right hemisphere, no } \\
\text { epileptiform discharges }\end{array}$ & $\begin{array}{l}\text { Dex, } \\
\text { prednisone }\end{array}$ & $\begin{array}{l}\text { Partial with mild } \\
\text { dysarthria, abnormal } \\
\text { gait but independent } \\
\text { ambulation }\end{array}$ & $\begin{array}{l}\text { Complete } \\
\text { remission of } \\
\text { ALL, residual } \\
\text { neurologic } \\
\text { deficits }\end{array}$ \\
\hline
\end{tabular}

MRI, magnetic resonance imaging; EEG, electroencephalogram; ALL, acute lymphoblastic leukemia; dex, dexamethasone; methylpred, methylprednisolone. 